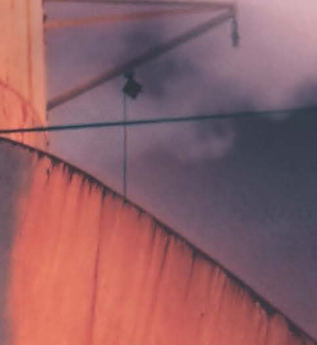

African perspectives on selected marine, maritime and

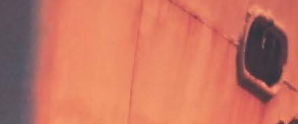

)
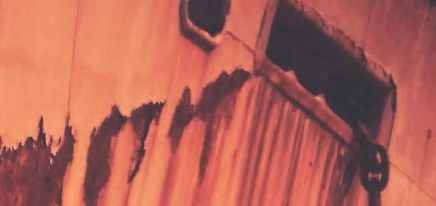

:

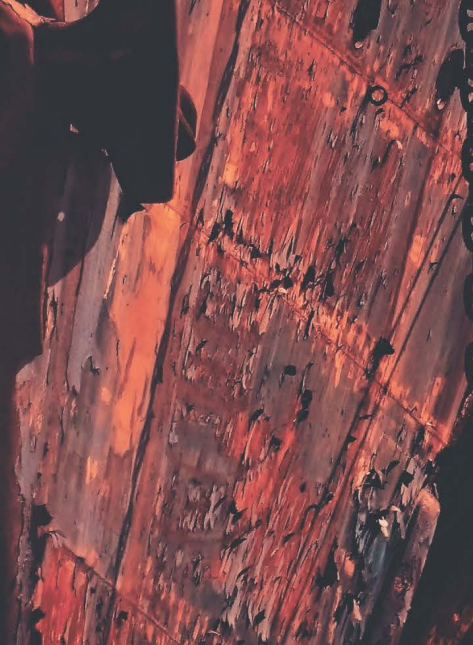

Patrick Vrancken \& Char! Hugo (Eds)

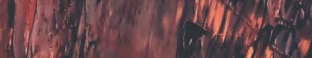

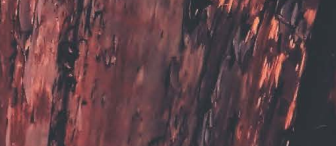
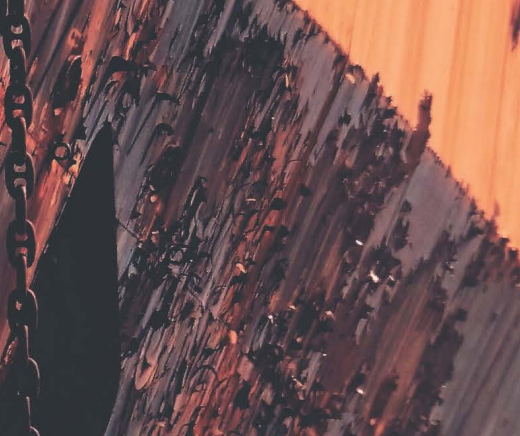
international trade law topics 


\title{
SLIPPING THROUGH THE NET: REFORMING SOUTH AFRICAN FISHERIES LAW ENFORCEMENT
}

\author{
HENNIE VAN AS* \\ CAMERON CORDELL ${ }^{\star \star}$
}

* Professor in Public Law and Director of the FishFORCE Fisheries Law Enforcement Academy, Nelson Mandela University, and Honorary Senior Fellow, Australian National Centre for Ocean Resources and Security (ANCORS), Faculty of Law, Humanities and the Arts, University of Wollongong, Australia.

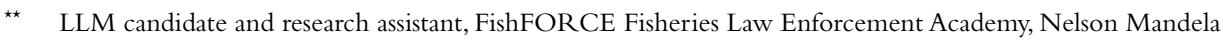
University. 


\section{INTRODUCTION}

The first annual review of organised crime in Southern Africa ${ }^{1}$ showed that the smuggling and illegal importation of goods and counterfeit commodities is one of the most prevalent organised criminal activities in the region. ${ }^{2}$ In many instances, these activities are undertaken by so-called "professionals"3 as part of a system that sees marine living resources being smuggled out of the country while drugs and other wares, such as cigarettes, are being smuggled into the country. The link between the illegal wildlife trade (and marine living resources in particular) and drug trafficking is strong. In the Western Cape, the relationship between abalone poaching and crystal methamphetamine, known as "tik", has been called a "marriage of convenience". ${ }^{4}$

Criminal activities in the fisheries sector are often regarded as synonymous with illegal fishing, which many countries do not view or prosecute as criminal offences, but rather as a fisheries management concern, attracting low, and usually administrative, penalties. ${ }^{5}$ As a result, organised criminal syndicates engage in fisheries crime with relative impunity due to low risk and high profits as well as uncoordinated and ineffective domestic and cross-border law enforcement efforts.

South Africa's law enforcement agencies, in particular its fisheries control officers (FCOs), have been struggling to curb the illegal harvesting of abalone at the hands of poachers and transnational crime syndicates. ${ }^{6}$ The country's stock of wild abalone is on the brink of extinction ${ }^{7}$ due predominantly to wide-scale illegal harvesting by poachers. Annually, tons of poached abalone are confiscated along with numbers of people being arrested and property seized, yet the plundering

1 Hübschle Organised Crime in Southern Africa: First Annual Review (2010).

2 ibid 13.

3 ibid 14.

4 ibid 30.

5 UNODC "Bringing to light the perfect storm of illegal activities in the fishing sector" (undated) https://www.unodc.org/unodc/about-unodc/campaigns/fisheriescrime.html (20-01-2019).

6 Redpath "Poached close to extinction" 2002 Focus http://hsf.org.za/resource-centre/focus/issue-25-firstquarter-2002/poached-close-to-extinction (20-01-2019).

7 Villette “Abalone poaching 'seen as easy way out of poverty for youth"” IOL (15-06-2017) https://www.iol.co.za/ capetimes/news/abalone-poaching-seen-as-easy-way-out-of-poverty-for-youth-9794638 (20-01-2019). 
of abalone continues unabated. ${ }^{8}$ The involvement of organised crime and the high value of abalone has resulted in poachers resorting to more desperate and violent measures, ${ }^{9}$ operating in dangerous waters without proper scuba training or equipment. ${ }^{10}$ If caught, South Africa has a low rate of detention of abalone poachers and its justice system has been criticised for providing weak deterrence due to low fines and penalties as well as poor conviction rates. ${ }^{11}$ These issues are exacerbated by the prevalence of corruption and non-compliance within the agencies meant to combat such criminal activity. ${ }^{12}$

This chapter begins by briefly examining the environment of abalone poaching, why it is so difficult to combat it and why administrative corruption and a culture of non-compliance has taken root within the agencies involved. To do this, a brief foray into the development and entrenchment of poaching syndicates in South Africa's vulnerable coastal communities is necessary. Reference will then be made to the legislative instruments that give FCOs their powers as well as the legislation that seeks to prevent corrupt activities. A discussion of how to treat administrative corruption effectively will follow before possible solutions to attempt to remedy the situation are provided in the conclusion.

It should be noted at the outset, however, that the focus is not on providing a solution to the abalone poaching crisis itself, but rather on improving the efficacy of the (currently) ineffectual FCOs who are meant to combat that activity. From that perspective, the main issues discussed are the nature of administrative corruption and non-compliance, why the latter have become so entrenched within the ranks of those meant to uphold the laws and regulations and which reforms might address those problems, acknowledging immediately that any solution suggested will not be a panacea to corruption and non-compliance.

8 Hyman "The wild, wild Western Cape - where poachers are robbed by gangsters" Times Live (23-08-2017) https://www.timeslive.co.za/news/south-africa/2017-08-23-the-wild-wild-western-cape-where-poachers-arerobbed-by-gangsters/ (20-01-2019).

9 Hopkinson “Pleasures of perlemoen poaching” Business Day (29-10-2014).

10 De Greef "The poachers and the treasures of the deep: diving for abalone in South Africa" Guardian (19-08-2018) https://www.theguardian.com/environment/2018/aug/19/poachers-abalone-south-africa-seafood-divers (07-02-2019).

11 De Greef "Fishing for answers at poaching's ground zero" Mail and Guardian (15-08-2014) https://mg.co.za/article/2014-08-14-fishing-for-answers-at-poachings-ground-zero (20-01-2019).

12 Specific instances will be dealt with below. 


\section{ABALONE POACHING AND ORGANISED CRIME: AN INTRINSIC CONNECTION}

The rise of abalone poaching in South Africa is a relatively recent phenomenon. As a result, there was little to no legal limitation on the capture of abalone until it was realised during the mid-90s that South Africa's stocks were depleting beyond the point of sustainability. This explains why the Marine Living Resources Act (MLRA), ${ }^{13}$ which was developed in line with the 1982 United Nations Convention on the Law of the Sea (LOSC),${ }^{14}$ recognises abalone (Haliotis midae) as one of the most vulnerable stocks. Nevertheless, rampant illegal fishing between 1996 and 2003 has decimated the abalone resource, necessitating restrictions upon the total allowable catch (TAC) as well as limitations on the size of the abalone caught. This led to the setting of a TAC of just 282 tons in $2003^{15}$ and the total closure of the fishery in $2008 .{ }^{16}$ The fishery was subsequently reopened in July 2010, with TAC allocations of 150 tons in the 2009/2010 and 2010/2011 seasons that were conditional on a 15\% per annum reduction in poaching. However, the required reduction in illegal harvesting has not been achieved. In fact, it increased substantially. By 2014, it was estimated that poaching had increased by some $150 \%$, whilst a net $50 \%$ reduction in poaching was required under the rebuilding plan. ${ }^{17}$

When placing such restrictions upon the harvesting of abalone, the government failed to consider two factors adequately. First, the imposition of the restrictions on fishing placed restrictions upon the small-scale fishers ${ }^{18}$ living in or near coastal communities that required the resources for sustenance. Second,

1318 of 1998

141833 UNTS 3, (1982) 21 ILM 1261. Adopted: 10-12-1982; EIF: 16-11-1994.

15 Department of Environmental Affairs "Seas of change" (undated) https://www.environment.gov.za/sites/default/ files/docs/10ytearsreview_marine_coast.pdf (06-02-2019).

16 Department of Agriculture, Forestry and Fisheries (DAFF) Status of the South African Marine Fishery Resources (2014) 5 .

17 ibid 7.

18 In terms of $\mathrm{s} 1$ of the MLRA, the term "small-scale fisher" means "a member of a small-scale fishing community engaged in fishing to meet food and basic livelihood needs, or directly involved in processing or marketing of fish, who[:] (a) traditionally operates in near-shore fishing grounds; (b) predominantly employs traditional lowtechnology or passive fishing gear; (c) undertakes single day fishing trips; and (d) is engaged in consumption, barter or sale of fish or otherwise involved in commercial activity, all within the small-scale fisheries sector". 
abalone (and in particular the South African variety) is considered to be a delicacy in the Far East, ${ }^{19}$ resulting in increased demand for a scarce resource.

The rise of criminal poaching networks resulted from the overlap of those two issues. A culmination of factors, including the high prices on offer as well as the socio-political climate and attitudes around the rights and legalities of abalone fishing, fostered an environment for the illegal fishery to grow. ${ }^{20}$ When Far-Eastern crime syndicates moved into coastal communities that had been prohibited from fishing, offering competitive financial incentives to poach abalone, the traditional informal abalone fishery grew into a highly organised illegal fishery facilitated by international networks ${ }^{21}$ exporting the product to Hong Kong. This, in turn, led to the development of organised crime syndicates. This is, of course, a very simplified description of a complex and vast series of factors, which have resulted in the entrenchment of poaching syndicates that are also involved in gangsterism as well as drug and human trafficking.

Many of the factors that gave rise to the prevalence of abalone poaching within South Africa's coastal communities could have been avoided had the implications of the existing fisheries-law framework been considered, particularly regarding the role of the FCOs, who are often members of the communities in which the poaching syndicates have taken root.

There is a body of work that confirms that abalone poaching in South Africa is linked to organised and transnational crime, the fact that the latter is also involved in the smuggling of poached abalone out of South Africa being known for years. ${ }^{22}$ Steinberg notes that there is a large and highly efficient Chinese organised-crime network involved in the South African illicit trade in abalone. ${ }^{23}$ According to De Greef, the "international criminal groups, in particular the so-

$19 \operatorname{DAFF}(\mathrm{n}$ 16) 5.

20 De Greef and Raemaekers South Africa's Illicit Abalone Trade: An Updated Overview and Knowledge Gap Analysis (2014) 6-9.

21 Okes, Bürgener, Moneron and Rademeyer Empty Shells: An Assessment of Abalone Poaching and Trade from Southern Africa (2018) 5 .

22 Gastrow “Triad societies and Chinese organised crime in South Africa” Organised Crime and Corruption Programme, Institute for Security Studies Occasional Paper No 48 (2001).

23 Steinberg "The illicit abalone trade in South Africa" Institute for Security Studies (2005) 16. 
called 'triad gangs' are from East Asia and they are heavily involved in the illegal trade of abalone". ${ }^{24}$ South Africa is viewed by these criminal organisations as a gateway into the African continent for their expansion of smuggling networks. ${ }^{25}$ The illicit trade of abalone is one of the triad-organised criminal activities pursued in this country. ${ }^{26}$ An occasional paper entitled "Triad societies and Chinese organised crime in South Africa" illustrated the link between these triads and abalone poaching when it stated that

"[t]he Taiwanese-linked criminal group active in Cape Town was referred to as the 'Table Mountain Gang' at that stage. Police soon discovered that members of these triad societies were also operating in the Johannesburg/Pretoria area as well as in every harbour city in South Africa. Police investigations also revealed that the illicit trade in abalone constituted a major component of the Chinese organised criminal groups". ${ }^{27}$

It is alleged that there are Chinese nationals, who are based in South Africa, who coordinate the poaching of abalone between local communities and importers in Asia. ${ }^{28}$ They are also responsible for controlling the flow and prices of poached abalone. ${ }^{29}$

This research is backed up by the recent case involving a poaching syndicate operating from Port Elizabeth. In $S v$ Blignault, ${ }^{30}$ the court stated that " $[\mathrm{t}] \mathrm{he}$ scale of [this] enterprise's activities extended far beyond provincial boundaries and establishes the reach of its organisational tentacles". ${ }^{31}$ Of the nine persons arrested in this matter, two were Chinese citizens, who claimed to be economic migrants. The testimony of these foreign nationals given in a separate trial $^{32}$ demonstrates

24 De Greef and Raemaekers (n 20) 6. "Triads" are defined as "ancient secret criminal societies which trace their roots to 17 th century China" (Snyman and Wagener "The role of the Chinese triads in South African organised crime" 1997 Acta Criminologica 107).

25 Snyman and Wagener (n 24) 112.

26 ibid.

27 Gastrow (n 22) 2.

28 Lau "An assessment of South African dried abalone Haliotis midae consumption and trade in Hong Kong" TRAFFIC International (2018) 15.

29 Gastrow (n 22) 5-6.

30 [2019] JOL 44135 (ECP).

31 par 9.

$32 S v$ Blignault 2018 (1) SACR 587 (ECP) par 5-6. 
that human trafficking may also be taking place to fuel the abalone poaching trade. Indeed, it was shown in evidence that the Chinese nationals involved were from impoverished communities in China, were promised well-paid jobs in South Africa and were then kept in "horrific conditions". ${ }^{33}$ In addition, it was shown that a lot of the abalone being processed by the syndicate did not originate from the Eastern Cape's coastal waters, but rather from the waters off the shores of the neighbouring Western Cape. ${ }^{34}$ In evidence, the link between abalone and drug trafficking was further confirmed, with some of the "workers" at the processing plant being paid in drugs rather than money. ${ }^{35}$

The case also suggests that the operation of the law regarding the poaching of abalone, in particular, appears not to be a deterrent against the activities of poaching syndicates. Indeed, Blignault himself was the subject of previous convictions for possession of abalone, but had continued with his illegal activities. ${ }^{36}$ The court viewed the matter in such a serious light that it stated that " $[t]$ he time had arrived for a complete reassessment of sentencing options ... The plunder continues unabated and the stage has been reached for appropriate sentences to stem the poaching tide". ${ }^{37}$

The entrenchment of the syndicates inside the coastal communities has created an environment of perceived impunity within these areas. As a result, poaching activities, that were once clandestine operations taking place under cover of night, are now widely practised in the light of day, in full view of the public and law enforcement officials. ${ }^{38}$

33 ibid 6.

34 Blignaut (n 30) par 6.

35 Dorfling "Perlemoen-sindikaat: Baasbrein het met dwelms betaal” Die Burger (24-01-2019) https://www.netwerk24. com/Nuus/Hof/perlemoen-sindikaat-baasbrein-het-met-dwelms-betaal-20180920 (28-01-2019).

36 Blignault (n 30) par 7.

37 ibid.

38 SA People News "Shocking Revelations of Blatant Abalone Poaching in South Africa" (30-12-2018) https://www.sapeople.com/2018/12/30/shocking-revelations-on-blatant-abalone-poaching-in-south-africa/ (24-01-2019). 
In addition, there is ample evidence that abalone from South Africa has traditionally been bartered for the ingredients of Mandrax 39 and later "tik", 40 imported from Asia. This straight exchange of commodities leaves no paper trail because there is no exchange of money, making it harder to track criminals involved in such dealings. There is a hierarchy and culture that has developed around these illicit trafficking activities, with the Chinese triads sitting at the apex and local dealers at street level selling the drug. Similarly, the poaching of abalone is done by local fishermen. This system is a highly effective one, particularly because the drug dealers and poachers do not know the identities of those above them in the chain. As a result, higher ranks of the abalone syndicate remain largely untouched due to each level of this complex system working in anonymity. In other words, the higher-ranking members of the syndicates remain above any consequences because there is usually insufficient evidence against them.

\section{THE CORRUPTION AND INEFFICIENCY OF FISHERIES LAW ENFORCEMENT}

Abalone poaching in South Africa remains one of the most serious and entrenched forms of fisheries-crime violations. In March 2018, the Western Cape High Court handed down judgment in $S v$ Miller, ${ }^{41}$ where the learned judge noted that

\footnotetext{
"[i]t must be said that the alarming fact is that poaching of large quantities of undersized abalone continues unabated. The sentences handed down by the lower courts...seem to have been no more than an occupational hazard taken into account by the unlawful enterprises as part of their necessary running expenses". ${ }^{42}$
}

The fact that court-imposed sanctions do not act as a deterrent to the continued poaching of abalone stocks in the South African coastal waters is an inefficiency mirrored throughout the fisheries law enforcement chain. In the same month as the Miller judgment, nine FCOs who were employed as compliance

\footnotetext{
39 a combination of methaqualone, cannabis and tobacco.

40 Okes (n 21) 5.

412018 (2) SACR 75 (WCC).

$42 S v$ Miller and Others [2018] 2 All SA 488 (WCC) 33.
} 
officers by the Department of Agriculture, Forestry and Fisheries (DAFF) were arrested by the Directorate for Priority Crimes Investigation ("the Hawks") on charges of being directly involved in organised crime syndicates pertaining to abalone poaching. ${ }^{43}$

The presence of corruption within DAFF is not limited to ground-level FCOs but seems to have spread throughout the entire chain of command, with allegations of corruption within the fisheries sector even being levelled at the Presidency. In 2018, it was alleged that former President Jacob Zuma had, during the course of his tenure, received a bribe of R1 million aimed at him not replacing the Minister of Agriculture, Forestry and Fisheries, who was in turn implicated in corrupt activity involving the sale of confiscated abalone. ${ }^{44}$ The operations of DAFF have further been hampered by prolonged in-fighting between the heads of department, with the result that

"[t]he department has spent tens of millions of rands on legal fees for both officials, in some cases hiring opposing sets of counsel. In the last two years, the department has also commissioned at least three forensic reports into corruption, although even these have been tainted by allegations of improper influence.

From both sides, there are claims that the department has been 'captured' by private interests, ranging from tenderpreneurs to abalone poaching syndicates". ${ }^{45}$

While this evidence demonstrates the presence of active organised crime, corruption and misadministration within the department that is expected to protect the marine living resources, passive corrupt acts have also taken root among FCOs, in most cases via non-compliance with regulations. This can take the form of overlooking a violation or failing to inspect vessels with due diligence, often in

43 Du Plessis "Hawks swoop on syndicates" Netwerk24 (12-032018) https://www.netwerk24.com/ZA/HermanusTimes/Nuus/hawks-swoop-on-syndicates-20180307-2 (20-01-2019).

44 News24 “'R1m bribe' for Zuma exposes crisis levels of abalone poaching DA" News24 (25-03-2018) https://www. news24.com/SouthAfrica/News/r1m-bribe-for-zuma-exposes-crisis-levels-of-abalone-poaching-da-20180325 (30-01-2019).

45 De Greef "Fisheries department rots from the top" GroundUp (12-11-2018) https://www.groundup.org.za/article/ fisheries-department-rots-top/ (30-01-2019). 
exchange for gratification. ${ }^{46}$ This "culture of non-compliance" ${ }^{47}$ has had negative consequences on several fronts.

First, a failure to combat the spread of abalone poaching syndicates effectively has allowed them to take root within coastal communities, increasing connected crimes such as drug trafficking, money laundering, tax evasion ${ }^{48}$ and gang violence within their areas of operation. The long-term involvement of so many individuals in this illicit economy and their exposure to other related crimes makes them highly vulnerable to a collapse in this economy, leaving them without the skills, relationships and networks to secure lawful employment. ${ }^{49}$

Second, apart from the environmental damage caused by the removal of the abalone stocks, the failure could be catastrophic for the South African fisheries industry as a whole because it robs the economy of potential revenue that could be gained through a sustainable abalone fishery.

Third, the lack of consequences for corrupt activities and organised crime has meant that the systems in place cannot effectively deal with curbing the theft of abalone stocks. As a result, extensive reform is required regarding how abalone poaching is investigated and how the officials meant to combat the crime are selected and trained.

\section{Corruption (in brief)}

It is often overlooked that, at the theoretical level, "corruption" is a catchall term for different types of conduct that contribute to personal gratification at the expense of ethical or moral duty. "Corruption" within the South African government is an issue which has been at the forefront of public consciousness over at least the past decade. This is predominantly due to large-scale corruption

46 Sundström "Covenants with broken swords: Corruption and law enforcement in governance of the commons" 2015 Global Environmental Change 253 256-258.

47 See below. See also Villegas "Disobeying the law: The culture of non-compliance with rules in Latin America" 2012 Wisconsin International Law Journal 263.

49 ibid.

50 See, for example, Transparency International “What is corruption?” (undated) https://www.transparency.org/whatis-corruption (2018-07-28). 
scandals that have shaken even the highest levels of government, such as allegations of state capture, ${ }^{51}$ the near collapse of the South African Social Security Agency through corrupt dealings ${ }^{52}$ as well as the deaths of mentally-ill patients in state care caused by corrupt and administrative mismanagement in the Life Esidimeni saga. ${ }^{53}$ These are, however, all examples of what is known as "grand corruption", which can be defined as "high-level power that benefits the few at the expense of the many, and causes serious and widespread harm to individuals and society". ${ }^{54}$

At the other end of the corruption spectrum is so-called "petty corruption", defined as "[e]veryday abuse of entrusted power by public officials in their interactions with ordinary citizens, who often are trying to access basic goods or services in places like hospitals, schools, police departments and other agencies...". 55 This is most commonly illustrated with reference to small bribes being paid to traffic officials upon being pulled over. Clearly, petty corruption fits the actions of corrupt FCOs more than grand corruption, where bribes are paid to corrupt officials to overlook abalone catches or warn poaching syndicates of police raids (although it will be shown later that grand corruption within DAFF is also an issue).

Corruption within FCOs also takes the form of "administrative corruption" or "the abuse of roles, powers, or resources found within public bureaucracies". ${ }^{56}$ In terms of the regulation of fisheries, FCOs can commit corrupt acts by, for example, approving illegal catches or allowing permits to fish in marine-protected areas (MPAs) to known members of poaching syndicates. According to the UN

51 See, generally, Public Protector State of Capture Report (2016).

52 Munusamy "Sassa crisis in concourt: The guardians, the people and the predator state" Daily Maverick (16-03-2017) https://www.dailymaverick.co.za/article/2017-03-16-sassa-crisis-in-concourt-the-guardians-the-people-and-thepredator-state/ (28-07-2017).

53 Malan and Msomi “\#LifeEsidimeni judge: ‘Government violated the Constitution”” Bhekissa (19-03-2018) https://bhekisisa.org/article/2018-03-19-00-lifeesidimeni-settlements-for-families-announced (28-07-2018).

54 Transparency International “Anti-corruption glossary: grand corruption” (undated) https://www.transparency.org/ glossary/term/grand_corruption (20-01-2019).

55 ibid.

56 Johnson "Administrative corruption" in Badie, Berg-Schlosser and Morlino (eds) International Encyclopaedia of Political Science (2011) 481 
Office on Drugs and Crime (UNODC),${ }^{57}$ corruption in the fisheries sector can manifest itself as:

"Active bribery - the promise, offering or giving to a national public official... of an undue advantage, in order to act or refrain from acting in matters relevant to official duties.

Passive bribery - the solicitation or acceptance by a public official ... of an undue advantage, in order to act or refrain from acting in matters relevant to official duties.

Embezzlement - theft or misappropriation of property, funds, securities or any other item of value entrusted to a public official in his or her official capacity.

Abuse of functions - performance of, or failure to perform, an act in violation of the law by a public official in order to obtain an undue advantage.

Trading in influence - abuse of a public official's influence with an administration, public authority or State authority in order to gain an advantage.

Illicit enrichment - a significant increase in assets of a public official that cannot reasonably be explained as being the result of his or her lawful income.

Money laundering - the concealment of the origins of corruptly obtained money, often by means of transfers involving foreign banks or legitimate businesses.

Concealment - hiding or continued retention of property that has resulted from corruption". ${ }^{58}$

The above does not mean that the lines between the types of corruption are clear cut. Rather, the different types of corruption live in a symbiotic relationship, feeding and nourishing each other. ${ }^{59}$ As such, low-ranking officials who perceive high-ranking members of the executive as partaking in corrupt acts without sanction are thereby encouraged to indulge in petty corruption. After being promoted (assuming a situation where corruption is endemic), they then turn to administrative corruption, routinely departing from the prescribed administrative

57 UNODC Rotten Fish:A Guide on Addressing Corruption in the Fisheries Sector (2018) 3.

58 ibid.

59 See Mashali "Analyzing the relationship between perceived grand corruption and petty corruption in developing countries: case study of Iran" 2012 International Review of Administrative Sciences 775. 
procedure for personal gain. Finally, if and when appointed to high-level posts in government, they perpetuate the culture of grand corruption, which in turn feeds the cycle from the base again. ${ }^{60}$

\section{Culture of non-compliance}

Non-compliance occurs when state officials choose not to enforce legal requirements and obligations. This can be for personal benefit (in which case the act could be said to be corrupt in nature) or for a number of sociological reasons. When such acts of non-compliance reach a stage that a failure to abide by a rule or regulation is systematic, then it can be said that a "culture of non-compliance" has developed.

In other words, a "culture of non-compliance" exists where the enforcement of a law is routinely abandoned to the point that the existence of the law can be said to be nothing more than fiction. With the entrenchment of this disregard of rules and procedures, particularly within the law enforcement agencies, it becomes increasingly difficult to combat criminal activities because the officers meant to investigate crimes are generally compromised. Corrupt acts perpetrated by state officials within structures where a culture of non-compliance prevails have generally been normalised to the extent that the act in question (for example, taking a bribe or doctoring inventories) is no longer viewed as morally or legally wrong by those within the system. ${ }^{61}$

Villegas, writing within a South American context, notes that there are three perspectives on how cultures of non-compliance develop. ${ }^{62}$ The first is the strategic perspective, whereby an actor weighs up the pros and cons of obeying and abandoning a rule or procedure and concludes that the benefit of disobedience is greater or that the cost of compliance is too great. ${ }^{63}$ Secondly, cultural norms might make actors consider their duty to their community to be greater than the duty to obey a rule viewed as being imposed upon the members

\footnotetext{
60 ibid 785.

61 Passas "Fighting corruption" (16-08-2015) https://www.youtube.com/watch?v=d4Dj0qdWLnk (20-01-2019).

62 Villegas (n 47) 263.

63 ibid 264.
} 
of that community. ${ }^{64}$ Finally, non-compliance can be a political act of resistance to a government considered to be corrupt. ${ }^{65}$ It seems that the development of the culture of non-compliance within the ranks of FCOs has resulted from a combination of the first two perspectives. Indeed, corrupt officials are often working towards the preservation of self-interest and otherwise feel more affinity towards the community members, the activities of whom they are meant to investigate, than the agency that employs them.

A culture of non-compliance has been said to exist within the ranks of marine living resources inspectors since as early as 2001, when 18 Marine and Coastal Management (MCM) officials ${ }^{66}$ were implicated in a trial involving the poaching of West Coast rock lobster by the Hout Bay Fishing Company (belonging to one Bengis) ${ }^{67}$ The extent of corrupt activities among government officials expected to combat fisheries crime was revealed when a large number of officials turned out to be implicated in such a high-profile case. In research conducted in 2015 by Sundström, ${ }^{68}$ during which senior officials were interviewed on the prevalence of corruption within the ranks of FCOs, it was stated that "respondents give a uniform image of the almost endemic state of bribery" ${ }^{69}$ Those interviewed claimed that inspectors were primed with gifts of fish by fishers seeking to avoid complying with the MLRA Regulations. ${ }^{70}$ The amount of the fish given would then increase over time, before monetary gratification is utilised. ${ }^{71}$ Furthermore, FCOs are often friends and family of local fishers who are involved with poaching syndicates, particularly in problem areas such as Gansbaai. ${ }^{72}$ At the street level, most of these violations appear to be simply inaccurate declarations of catches. When

\footnotetext{
64 ibid 265.

65 ibid.

66 the forerunners of the FCOs under DAFF.

67 Hauck and Kroesser "Fisheries compliance in South Africa: A decade of challenges and reform 1994-2004" 2006 Marine Policy 74 75. The Bengis matter would go on to have serious implications for the transnational combating of fisheries crime, but that aspect is not relevant to the subject at hand. 
poaching syndicates are involved, however, the service rendered in exchange for gratification is often far more sinister, with FCOs informing poachers of police raids, removing or tampering with evidence to scupper a case against a poacher or hiding poached stocks from the police. ${ }^{73}$ As recently as 2018, 18 DAFF officials were arrested for being actively involved in abalone poaching syndicates, not only selling seized abalone stocks back to the people they were taken from, but also escorting poached abalone through police roadblocks to evade detection. ${ }^{74}$

The culture of non-compliance that has taken root in DAFF is, based upon the above evidence, both strategic and cultural in nature. It is strategic in that FCOs weigh up the cost of either obedience or disobedience and decide that violating their duty is the more beneficial option. During Sundström's interviews, FCOs stated in their responses that officers caught with illegal abalone on their persons continued to work unfettered within the department, while whistle-blowers were usually ousted. ${ }^{75}$ This lacklustre approach to combating corruption within the department has resulted in it being more beneficial for FCOs to either ignore or participate in corrupt activity than to combat it. ${ }^{76}$ This is not helped by the lack of potential career advancement. Furthermore, the perception that even officials at the top of the hierarchy are committing corrupt acts has led to a perception that corruption is a necessary part of the job. From a cultural perspective, it has already been pointed out that FCOs often have close connections with friends and families within the coastal communities where poaching syndicates operate. This creates a conflict of interest where officials may be tempted to support these connections rather than uphold their duty to the State. A discussion of the legal instruments in place to combat corrupt activity must take place against this background of corruption and a culture of non-compliance.

73 ibid.

74 Pitt "Marine inspectors bust for allegedly aiding abalone syndicate" News24 (06-03-2018) https://www.news24. com/SouthAfrica/News/marine-inspectors-bust-for-allegedly-aiding-abalone-syndicate-20180306 (20-01-2019).

75 Sundström (n 46) 259.

76 ibid. 


\section{LAW}

\section{Marine Living Resources Act}

The main statute governing the South African fisheries is the MLRA, which deals predominantly with "the conservation of the marine ecosystem, the longterm sustainable utilisation of marine living resources and the orderly access to exploitation, utilisation and protection of certain marine living resources..." ${ }^{77}$ It does this by providing for the management and control of fishing rights on both a micro and macro level. Section 9 of the MLRA gives the Minister responsible for fisheries the power to appoint officials known as FCOs. ${ }^{78}$ These FCOs may be appointed from "any organ of state". ${ }^{79}$ In practice, these officials are found as a unit within DAFF. The powers of FCOs are defined in section 51 of the MLRA. While they are able to enter, search and seize the property of "any vessel" with a warrant, ${ }^{80}$ they are also granted extensive powers that they are able to exercise without a warrant. Those powers include the power to stop vessels, ${ }^{81}$ muster the crew, ${ }^{82}$ require the master to produce a licence and the records of fish caught ${ }^{83}$ as well as escort a vessel to port for the purposes of investigating a violation of the MLRA or its Regulations, where there is a reasonable suspicion that such a violation has occurred. ${ }^{84}$ FCOs also have powers of search and seizure of any vessel they reasonably suspect has committed illegal fishing activity in terms of the Act. ${ }^{85}$

The MLRA Regulations complement the Act by providing, for instance, that the master of a vessel must comply with any legitimate order by an $\mathrm{FCO}^{86}$ and that the costs incurred by an FCO while supervising the offloading or

\footnotetext{
77 long title of the MLRA.

78 s 9.

79 s $9(1)$.

80 s $51(1)$.

81 s $51(2)(a)$.

82 s $51(2)(e)$.

83 s $51(2)(\mathrm{f})$.

84 s 51(2)(j).

85 See, generally, s 51(3).

86 See, generally, reg 83(1).
} 
transhipment of goods or fisheries stocks are to be borne by the captain of the vessel. ${ }^{87}$ The FCOs are themselves subject to regulations in that, for instance, they are required to notify a vessel of their intention to board via radio or any other appropriate signal ${ }^{88}$ and they may not require vessels to stop or manoeuvre while they are in the process of fishing, shooting or hauling. ${ }^{89}$

The restrictions on the harvesting of abalone are also of import in terms of this discussion. While abalone as a species is not mentioned within the main body of the MLRA itself, the Minister is given the power to determine the TAC of a particular species with regard to small-scale, recreational, local commercial and international commercial fishing. ${ }^{90}$ It is in the exercise of that power that the Regulations for the Protection of Wild Abalone ("the Abalone Regulations") 91 were promulgated. The Regulations seek not only to suspend the activities of the abalone industry, but also to provide for the implementation of measures to bolster the failing abalone stocks. ${ }^{92}$ In addition, the Regulations set out specific areas ${ }^{93}$ wherein diving and the possession of prohibited materials is prohibited without the specific authorisation from the Minister. ${ }^{94}$ The penalty for committing an act that constitutes an offence in terms of the Abalone Regulations is either a fine of up to R 500000 or imprisonment not exceeding two years. ${ }^{95}$ As far as the activities listed under regulation $3(3)^{96}$ are concerned, should they be conducted

\footnotetext{
$87 \operatorname{reg} 83(3)$.

$88 \operatorname{reg} 84(1)$.

$89 \operatorname{reg} 84(2)$.

90 s 14 of the MLRA.

91 GN R62 in GG 30716 of 01-02-2008.

$92 \operatorname{reg} 2$.

93 annexure 1 of the Abalone Regulations. The areas are: the Bird Island Marine Protected Area; Quoin Point to Danger Point, extending two nautical miles seaward from the high watermark; Dyer Island, extending one nautical mile from the high watermark; Venus Pool to Cape Point and from Cape Point to Olifantsbospunt, extending 2 nautical miles seaward from the high watermark, but excluding Bellows Rock; and Robben Island, extending 1 nautical mile from the high watermark.

94 reg 3. See, however, the exceptions in reg 4.

$95 \operatorname{reg} 5(1)$.

96 The activities include: "(a) scientific research and monitoring; (b) white shark-cage diving; (c) commercial kelp harvesting; (d) sea ranching; (e) salvage operations; [and] (f) maintenance of legal underwater infrastructure ...".
} 
without having obtained a permit from the Minister as per the Regulations, the fine is R 100000 with the alternative of one year imprisonment. ${ }^{97}$

\section{Prevention of Organised Crime Act}

The Prevention of Organised Crime Act (POCA) ${ }^{98}$ is often utilised in conjunction with the MLRA when combating abalone poaching. The reasons for this are fairly self-explanatory when one considers the prevalence of organised poaching syndicates having taken root within coastal communities in South Africa. POCA not only provides for the offences of racketeering and money laundering but goes further in that it provides for the seizure of property and profits derived from illicit activities.

Of primary importance with regard to abalone poaching are the provisions relating to racketeering activities. Section 2 of POCA lays out a wideranging framework whereby any person who retains any property that amounts to the proceeds of "a pattern of racketeering activity", and who knows that such property is so derived, is guilty of an offence. "A pattern of racketeering activity" is defined for the purposes of POCA as

"the planned, ongoing, continuous or repeated participation or involvement in any offence referred to in Schedule 1 [of POCA], and includes at least 2 offences..., of which one of the offences occurred after the commencement of the Act... ". 99

As far as criminal gang activities are concerned, POCA makes it an offence, for instance, for any person who actively participates in or is a member of a criminal gang to wilfully aid and abet "any criminal activity committed for the benefit of, at the direction of, or in association with any criminal gang". ${ }^{100}$

POCA also provides extensively for the offence of corruption. It does this by setting out a general offence of corruption combined with specific offences

\footnotetext{
$97 \operatorname{reg} 5(2)$.

98121 of 1998.

99 s 1. Schedule 1 lists "dealing in, being in possession of or conveying endangered, scarce or protected game or plants or remains thereof in contravention of a statute of official ordinance".

100 s $9(1)(a)$.
} 
pertaining to public officials. In terms of these provisions, any persons within public office (such as FCOs in the employ of DAFF) are guilty of an offence of corruption if they accept, agree or offer to accept any gratification in exchange for committing an illegal or unethical dereliction of duty. ${ }^{101}$ The "gratification" can amount to money, goods or services. ${ }^{102}$ It should be noted that both parties within a corrupt act, the briber and bribee, fall within the prohibition of corrupt activity. ${ }^{103}$

It must also be pointed out that POCA provides for confiscation and preservation orders, ${ }^{104}$ which assist in preserving evidence of the commission of poaching activities prior to and during prosecution or forfeiting the proceeds of unlawful activities to the State.

\section{ISSUES}

Despite the comprehensive attempts to control and regulate the South African fishing industry, the issue of non-compliance by both the public and the FCOs themselves has demonstrated that the existing legislative framework is insufficient to combat fisheries crimes effectively.This has several knock-on effects.

First, the failure of DAFF to secure compliance with fisheries regulations and the existing tensions within the communities in which the FCOs operate have resulted in the entrenchment of poaching syndicates in these communities. As a further result, this has led to increased gangsterism as well as the introduction of drugs and, in some cases, human trafficking.

Second, the failure to ensure compliance has been shown to have a negative effect on the delicate ecosystems that exist in South Africa's coastal waters. The removal of the species from its native habitat has been cited as "detrimental", ${ }^{105}$

101 s 3.

102 s 1 .

103 s 3 clearly states that both offering and receiving gratification are prohibited.

104 ss 18 and 38 respectively.

105 Pariona "The ill effects of abalone poaching in South Africa" (01-08-2017) https://www.worldatlas.com/articles/ the-ill-effects-of-abalone-poaching-in-south-africa.html (20-01-2019). 
having knock-on effects on other species, which in turn cause further difficulties for the members of local communities who rely upon the sea for livelihood and sustenance.

Third, while FCOs' powers seem quite effective when one reads the legislation, those powers are in reality exceptionally weak and reliant upon the support of the members of the South African Police Services (SAPS). While FCOs are able to enter vessels and premises as well as search and seize property, any evidence collected needs to be handed over to the police as soon as possible. Furthermore, there are holes within the MLRA in terms of how FCOs are able to operate. The best example is the question of whether FCOs (as peace officers) are able to apply for a search warrant in terms of the Criminal Procedure Act (CPA). ${ }^{106}$ It seems reasonable to think that, when FCOs are given the power to enter premises or board a vessel with a warrant, they should be able to apply for the warrant in question. However, this does not appear to be the case. In practice, some magistrates entertain applications from FCOs but, in many instances, they require SAPS officials to apply for the warrants on behalf of the FCOs, a task that is, in many instances, completed with difficulty. ${ }^{107}$ For that reason, it can be argued that FCOs are largely ineffective and dependent on the SAPS in the fulfilment of their legislative mandate.

In addition, FCOs have no powers to investigate. In practice, it means that, after they have apprehended suspects and completed statements, they have to hand the case over to the SAPS. In most instances, they have no idea of how, or even whether, cases are progressing. The demoralising effect of this lack of interagency cooperation is well documented. ${ }^{108}$ Furthermore, there is a proliferation of law enforcement agencies attempting to address abalone poaching. In the South-Western Cape, there are the SAPS, DAFF, Cape Nature, SANParks and the Overstrand Municipality Law Enforcement Unit. In addition, the City of Cape Town has marine units in its Metro Police as well as in its Law Enforcement

10651 of 1977.

107 Snijman and Van As (2018) (Unpublished legal opinion to DAFF).

108 e-mail dated 13-07-2018 from a Senior FCO to the Director of FishFORCE and interviews with senior officials at DAFF in 2017/18. 
Department. However, these units do not collaborate, they do not liaise with each other and they do not have common objectives. ${ }^{109}$ In the words of one official employed by the City of Cape Town: "We chase numbers. CIVOC ${ }^{110}$ wants numbers. They are not interested in quality".

All of the above speaks towards the failure of the MLRA to provide an effective and independent framework to deal with illegal fishing. The lack of clear powers given to FCOs has resulted in poaching syndicates feeling that they can commit their crimes with impunity while also leading FCOs themselves to be non-compliant in the fulfilment of their duties. It is noteworthy that this is not a problem unique to South Africa. Indeed, Njaya notes in the Malawian context that "co-management arrangements are characterized by unequal power distribution among these different actors, often resulting in the marginalization" of subsistence fishers. ${ }^{111}$

\section{POSSIBLE SOLUTIONS}

Legal reform is the only way forward to make FCOs more effective. This can be done by clarifying the powers already granted by the MLRA, such as the ability of FCOs to apply for search warrants, but also extending their powers of search, seizure and arrest as well as their power to set up roadblocks in order to make them more effective. This is especially important in view of the fact that inter-agency collaboration is required to set up such blockades and that the ability and availability of the agencies required to make this possible are often a source of frustration. This would also require the MLRA and its regulations setting a minimum standard of formal training. This is confirmed by a number of international bodies, which have identified proper training as a prerequisite for combating fisheries crime. Those bodies include the World Wide Fund for

109 interviews with members of the various units conducted on behalf of FishFORCE on 03-7-2018 and 17-08-2018 by HJ van As.

110 the Civilian Oversight Committee established in terms of s 64J of the South African Police Service Act (68 of 1995 , SAPSA).

111 Nadya "Analysis of power in fisheries co-management: Experiences from Malawi” 2012 Society and Natural Resources 652. 
Nature (WWF), ${ }^{12}$ the Food and Agriculture Organization of the United Nations $(\mathrm{FAO})^{113}$, Interpol $^{114}$ and UNODC. ${ }^{115}$

Another question to be answered, considering the current situation and the urgency of combating illegal fishing, is whether FCOs are best suited as a unit of DAFF or whether the body should be moved to a specialised unit of the SAPS dedicated to addressing fisheries crime as an element of organised crime. While it would seem prudent to house FCOs within the department responsible for fisheries, these officials are primarily fulfilling a policing function. Placing the agency within the SAPS would also solve some of the issues facing FOCs currently by formalising training in fitness, investigation and arrest, ${ }^{116}$ allocating powers such as applying for warrants ${ }^{117}$ and bringing expertise on the fisheries industry to other SAPS units such as the Hawks. Such a move might also assist in combating the culture of non-compliance and corruption that has taken root among the FCOs by bringing the unit under the oversight of bodies such as the Independent Police Investigative Directorate (IPID). ${ }^{118}$

An alternative is to designate FCOs as environmental management inspectors (EMIs) in terms of the National Environmental Management Act (NEMA). ${ }^{119}$ Such a move would result in minimum training requirements being set as well as an extension and clarification of the FCOs' powers, including the use of force for the purpose of stopping vessels, vehicles and aircraft. ${ }^{120}$ It would also confer upon the FCOs "all the powers of a member of the South African

112 WWF 2015 Annual Report (2015) 32 https://c402277.ssl.cf1.rackcdn.com/publications/832/files/original/WWF_ EFN_Annual_Report_FINAL_SPREAD.pdf?1445869889 (13-05-2020).

113 FAO Recent Trends in Monitoring, Control and Surveillance Systems for Capture Fisheries (2018) 58.

114 Interpol hosts annual police training symposiums, which include sessions aimed at improving marine law enforcement.

115 In 2016, Nelson Mandela University became a founding member of the UNODC's LETrainNET initiative, which promotes the exchange of training materials and courses between law enforcement organisations and tertiary institutions.

116 s 32 read with s 37 of the SAPSA.

117 s 25(1) of the CPA.

118 established by s 3(1) of the Independent Police Investigative Directorate Act (1 of 2011).

119107 of 1998

120 s $31 \mathrm{~J}(4)(\mathrm{b})$ of NEMA. 
Police Service in terms of section 13(8) of the South African Police Service Act, 1995". ${ }^{121}$ That would include the power to set up and conduct roadblocks in terms of the SAPSA. ${ }^{122}$ EMIs are also granted specific permission to apply to a court for a warrant. ${ }^{123}$ In addition, and most importantly, NEMA provides that EMIs may issue compliance notices, ${ }^{124}$ which must state that a person has failed to comply with relevant legislation and indicate the steps that must be taken to rectify the situation. ${ }^{125}$ Failure to comply with a compliance notice can result in a permit being revoked and the imposition of a fine not exceeding five million rand, with an alternative of 10 years imprisonment. ${ }^{126}$

In whatever form, legislative reform is required to secure the country's marine living resources for current and future generations through effective enforcement of the law.

\footnotetext{
121 See s 31J(7) of NEMA.

$122 \mathrm{~s} 13(8)(\mathrm{c})$ of the SAPSA.

123 s $31 \mathrm{~K}(4)$ of NEMA.

124 s 31L(1) of NEMA.

125 s 31L(2) of NEMA.

126 s $31 \mathrm{~N}(2)$ of NEMA.
} 